\title{
Conformational Change of Glyceraldehyde-3-phosphate Dehydrogenase Induced by Acetylleucine Chloromethyl Ketone is Followed by Unique Enzymatic Degradation
}

\author{
Mitsune Yamaguchi, * Yukihiro TsuchiYa, Kayoko Hishinuma, Toshiyuki Chikuma, and Hiroshi Hojo \\ Department of Hygienic Chemistry, Showa Pharmaceutical University; 3-3165 Higashitamagawagakuen, Machida, Tokyo \\ 194-8543, Japan. Received May 29, 2003; accepted September 22, 2003; published online October 1, 2003
}

\begin{abstract}
We have previously reported that acetylleucine chloromethyl ketone (ALCK), an inhibitor of acylpeptidehydrolase, induces the inhibition and degradation of glyceraldehyde-3-phosphate dehydrogenase (GAPDH) in the U937 cell extract. In the present study, the process of ALCK-induced GAPDH degradation was investigated. A kinetic study revealed that GAPDH was irreversibly inhibited by ALCK. ALCK treatment induced a change in the signal intensity of GAPDH in the near-UV region of the circular dichroism (CD) spectrum, and the fluorescence intensity of GAPDH at $330 \mathrm{~nm}$ increased to about $10 \%$ when excited at $280 \mathrm{~nm}$, suggesting that a significant conformational change of GAPDH was induced by ALCK. When the U937 cell extract was incubated with ALCK and the products were separated by SDS-polyacrylamide gel electrophoresis (PAGE), a 23-kDa fragment from GAPDH was detected by Western blotting using anti-GAPDH serum. When ALCK-treated GAPDH was incubated with protease fractions from the U937 cell extract, a 17-kDa fragment was also detected. Sequence analysis showed that the N-terminal amino acid sequence of the 23-kDa fragment was GKVKVG and that of 17kDa fragment was RDGRGAL. Therefore, ALCK-modified GAPDH is deduced to be digested at the peptide bond $\operatorname{Trp}_{195}-\mathrm{Arg}_{196}$. The protease activity liberating a 23-kDa fragment from ALCK-treated GAPDH was effective under the basic condition. Results suggested that ALCK binds to GAPDH to modulate the conformation of enzyme, which is susceptible to chymotrypsin-like protease activity.
\end{abstract}

Key words acetylleucine chloromethyl ketone (ALCK); glyceraldehyde-3-phosphate dehydrogenase; U937 cell extract; chymotrypsin-like protease

In our previous work, acetylleucine chloromethyl ketone (ALCK), an inhibitor of acylpeptide hydrolase (ACPH, EC 3.4.19.1), was shown to cause apoptosis of U937 cells ${ }^{1)}$ and to induce the inhibition and degradation of glyceraldehyde-3phosphate dehydrogenase (GAPDH) in U937 cells and its cell extract. ${ }^{2)}$ Recently, GAPDH has been found to be involved in various biological functions ${ }^{3)}$ such as membrane fusion, ${ }^{4)}$ microtubule bundling, ${ }^{5)}$ phosphotransferase activity, ${ }^{6}$ nuclear RNA export, ${ }^{7)}$ DNA replication, ${ }^{8)}$ and DNA repair ${ }^{9)}$ other than the its conventional role in glycolysis. Furthermore, the evidence linking GAPDH to apoptosis has been accumulating for close to 20 year. A strong GAPDH inhibitor, koningic acid ${ }^{10)}$ and antisense DNA for GAPDH ${ }^{11}$ induce apoptosis in neuroblastoma $\times$ glioma hybrid cells and cervical carcinoma cell lines, respectively, suggesting that inhibition of GAPDH at least partially induces apoptosis. However, the relationship between degradation of GAPDH and apoptosis is unclear. Therefore, the study on the mechanism of ALCK-induced degradation is important to afford the key to an understanding of the ALCK-induced apoptosis of U937 cells. It is not known at present what regulatory mechanisms exist in cells, which modulate the cellular localization and structure of GAPDH to control these diverse functions.

Recent extensive studies have demonstrated that there are two degradation systems for intracellular proteins. One is the ubiquitin-proteasome system, by which the short-lived and abnormal proteins are degraded, ${ }^{12)}$ and the other is the lysosome system, by which the long-lived proteins such as GAPDH are degraded. ${ }^{13)}$ To the best of our knowledge, the degradation of chemically modified GAPDH has not been reported.

In the present study, we attempted to obtain evidence supporting the ALCK-induced conformational change of
GAPDH, which is susceptible to proteolysis, and to identify the GAPDH fragments, by which the peptide bond digested was determined. Furthermore, protease involved in its digestion was partially characterized.

\section{MATERIALS AND METHODS}

Chemicals ALCK was synthesized from L-leucine chloromethyl ketone $\mathrm{HCl}$ (LCK, Sigma Chemical Co., St. Louis, MO, U.S.A.). ${ }^{1)}$ Human erythrocyte GAPDH, glyceraldehyde-3-phosphate (GAP) and acetylalanine $p$-nitroanilide (AANA) were purchased from Sigma Chemical Co. $\beta$-NAD was purchased from Oriental Yeast Co. (Tokyo, Japan).

Preparation of U937 Cell Extract and Purification of GAPDH A human leukemia cell line U937 was a gift from the Cell Resource Center for Biomedical Research Institute of Development, Aging and Cancer, Tohoku University (Sendai, Japan). In preparing the U937 cell extract, U937 cells were washed twice in ice-cold calcium- and magnesium-free phosphate buffered saline (PBS) and solubilized in PBS containing $0.05 \%(\mathrm{v} / \mathrm{v})$ Triton X-100 at $4{ }^{\circ} \mathrm{C}$ for $1 \mathrm{~min}$. These were then centrifuged at $10000 \mathrm{~g}$ at $4{ }^{\circ} \mathrm{C}$ for $10 \mathrm{~min}$, and the resultant supernatant was recovered as the U937 cell extract. GAPDH was purified by DEAE-5PW, CM-5PW (Tosoh, Tokyo, Japan) and Protein Pak 300 (Waters, Milford, MA, U.S.A.) from the U937 cell extract. ${ }^{2)}$ Protein concentration was determined by the Bradford method ${ }^{14)}$ using BSA as a reference standard.

Inhibition of GAPDH Activity by ALCK GAPDH activity was assayed according to the procedure of Dimmeler $e t$ $a .^{15)}$ with minor modifications. ${ }^{2)}$ For the inhibition test, GAPDH purified from the U937 cell extract was treated with 
various concentrations of ALCK in $20 \mathrm{mmol} / 1$ phosphate buffer ( $\mathrm{pH} 7.4)$ at $37^{\circ} \mathrm{C}$ in a total volume of $80 \mu$ l. It was then added to $120 \mu \mathrm{l}$ of $50 \mathrm{mmol} / 1$ prewarmed triethanolamine buffer ( $\mathrm{pH}$ 7.6) containing $50 \mathrm{mmol} / 1$ arsenate, $2.4 \mathrm{mmol} / 1$ glutathione, $0.4 \mathrm{mmol} / 1 \mathrm{NAD}$, and $0.9 \mathrm{mmol} / 1$ GAP. GAPDH activity was determined at $37^{\circ} \mathrm{C}$ for $3 \mathrm{~min}$ by measuring NADH production at $340 \mathrm{~nm}$.

Assay for Circular Dichroism (CD) and Fluorescence Spectra Commercially available human erythrocyte GAPDH was purified by a Sephacyl S-300 column and treated with $1 \mathrm{mmol} / 1 \mathrm{ALCK}$ for $37^{\circ} \mathrm{C}$ for $1 \mathrm{~h}$ and then applied to a PD-10 column (Amasham Bioscience, NJ, U.S.A.) to remove free ALCK. ALCK-treated GAPDH or untreated GAPDH was adjusted to a concentration of $1 \mathrm{mg} / \mathrm{ml}$ in $20 \mathrm{mmol} / 1$ potassium phosphate buffer ( $\mathrm{pH}$ 7.4). CD spectrum was measured using a J-600 spectropolarometer (Jasco, Tokyo, Japan) with $1 \mathrm{~cm}$ path length cell at $190-360 \mathrm{~nm}$ at $20^{\circ} \mathrm{C}$. Buffer effect was eliminated by subtracting its corresponding spectrum. Fluorescence emission spectrum excited at $280 \mathrm{~nm}$ was measured at $300-450 \mathrm{~nm}$ at $20^{\circ} \mathrm{C}$ using a RF-5000 spectrofluorophotometer (Shimadzu, Kyoto, Japan).

Detection of GAPDH Fragments Produced by Incubating U937 Cell Extract with ALCK The U937 cell extract $(0.1 \mathrm{mg} / \mathrm{ml})$ was incubated with $100 \mu \mathrm{mol} / 1 \mathrm{ALCK}$ with or without $100 \mu \mathrm{mol} / 1 \mathrm{TPCK}$ or TLCK at $37^{\circ} \mathrm{C}$ for $1 \mathrm{~h}$. Peptide fragments produced in the reaction were separated by $10 \%$ SDS-polyacrylamide gel electrophoresis (PAGE) and separated fragments were transferred to a PVDF membrane. The membrane was blocked in PBS containing $0.5 \%(\mathrm{w} / \mathrm{v})$ nonfat dried milk, probed with diluted mouse anti-GAPDH serum $(1: 2000)$ raised against human erythrocyte GAPDH, and stained using anti-mouse IgGs and the avidin-biotin-peroxidase color development system.

Determination of $\boldsymbol{N}$-Terminal Amino Acid Sequence of GAPDH Fragments Protease fractions releasing a $23-\mathrm{kDa}$ fragment from ALCK-treated GAPDH were partially purified from the U937 cell extract by Superose-6 gel filtration. ALCK-treated erythrocyte GAPDH $(0.1 \mathrm{mg} / \mathrm{ml})$ was incubated with the protease fractions $(0.1 \mathrm{mg} / \mathrm{ml})$ at $37^{\circ} \mathrm{C}$ for $0.5 \mathrm{~h}$. The reaction products were applied to a DEAE-5PW column $(21.5 \times 150 \mathrm{~mm}$, Tosoh, Tokyo) equilibrated with $20 \mathrm{mmol} / \mathrm{l}$ phosphate buffer $(\mathrm{pH}$ 7.4). The unbound protein fractions were concentrated and separated by 14\% SDSPAGE. Peptides were blotted to a poly (vinylidene difluoride) (PVDF) membrane, stained with Coomassie brilliant blue R250 (CBB) and analyzed for the amino acid sequence using a Procise 491 amino acid sequencer (PE Biosystems, CA, U.S.A.).

\section{RESULTS}

Kinetic Analysis of GAPDH Inhibition by ALCK Although ALCK had been found to inhibit GAPDH in our previous study, ${ }^{2)}$ its mode of inhibition remained unknown. Kinetic studies showed that ALCK inhibited GAPDH activity as a non-competitive inhibitor with respect to GAP (Fig. 1A), and as an uncompetitive inhibitor with respect to $\mathrm{NAD}^{+}$(Fig. 1B). These findings suggested that ALCK binds more tightly to GAPDH that is bound to NAD ${ }^{+}$than to free GAPDH.

CD and Spectrofluoriometric Spectra of ALCKTreated GAPDH Since ALCK was expected to affect GAPDH conformation, we compared between CD spectra of ALCK-treated and untreated GAPDH. CD spectra of ALCKtreated and untreated GAPDH were not different in the farUV region (data not shown). In the near-UV region, ALCKtreated GAPDH exhibited a change in signal intensity compared with untreated GAPDH (Fig. 2A). Data suggest that some changes in the orientation and/or microenvironment of aromatic residues in GAPDH may have been induced follow-
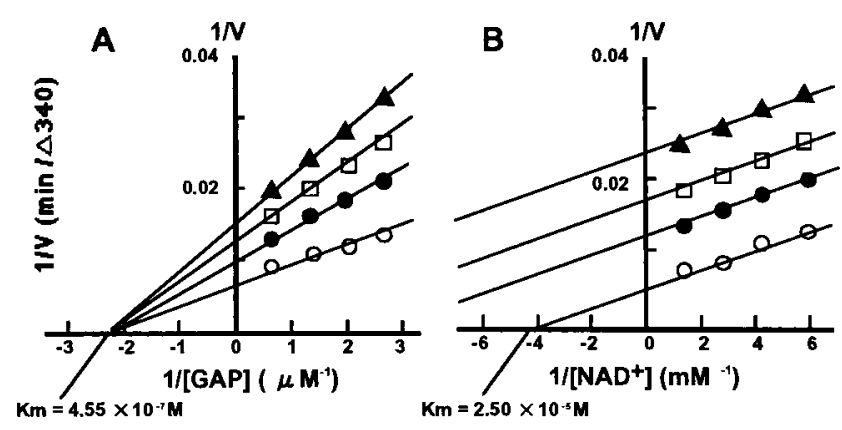

Fig. 1. Lineweaver-Burk Plots of GAPDH Inhibition by ALCK

GAPDH inhibition by ALCK was measured at various concentrations of GAP (A) or $\mathrm{NAD}^{+}$(B). Concentrations of ALCK were as follows; none (open circle), $20 \mu \mathrm{mol} / 1$ (closed circle), $30 \mu \mathrm{mol} / 1$ (open square), and $40 \mu \mathrm{mol} / 1$ (closed square).

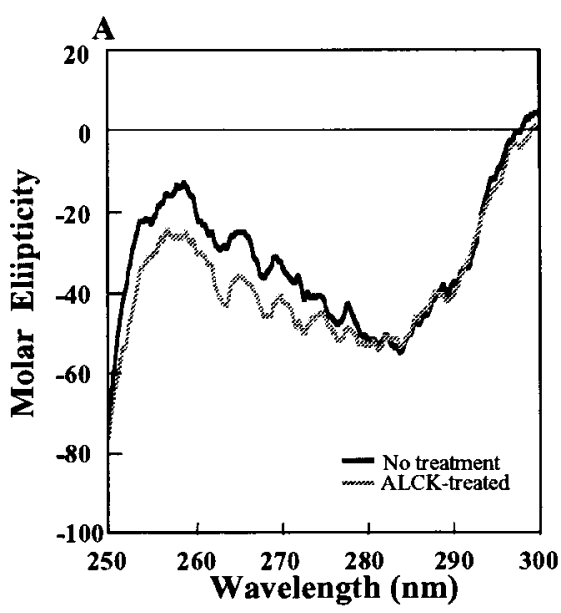

Fig. 2. Circular Dichroism (CD) and Fluorescence Spectra of ALCK-Treated and Untreated GAPDH

GAPDH was treated with $1 \mathrm{mmol} / 1$ ALCK for $1 \mathrm{~h}$, and then free ALCK was removed by gel filtration. CD spectra of ALCK-treated and untreated GAPDH were recorded (A) and fluorescence spectra of ALCK-treated and untreated GAPDH excited at $280 \mathrm{~nm}$ were recorded (B). 
ing ALCK treatment. Further evidence supporting the ALCK-induced conformational change of GAPDH was obtained from the comparison of intrinsic fluorescent properties between ALCK-treated and untreated GAPDH. When excited at $280 \mathrm{~nm}$, the fluorescence intensity of ALCK-treated GAPDH at $330 \mathrm{~nm}$ increased to $10 \%$ more than that of untreated GAPDH (Fig. 2B).

Analysis of GAPDH Fragments Produced by Incubation with ALCK The U937 cell extract was incubated with or without ALCK, and with ALCK-treated or untreated erythrocyte GAPDH $(36 \mathrm{kDa})$ at $37^{\circ} \mathrm{C}$ for $1 \mathrm{~h}$ (Fig. 3). Peptides produced in the two enzyme reactions were separated by SDS-PAGE and visualized by silver staining (Fig. 3A) and Western blotting using anti-GAPDH serum (Fig. 3B). A 23$\mathrm{kDa}$ fragment was observed by silver staining (lane 2, Fig. $3 \mathrm{~A}$ ) and clearly by Western blotting (lane 2, Fig. 3B) when the U937 cell extract was incubated with ALCK, but it was not observed when incubated without ALCK (lane 1, Figs. 3A, B). Incubation of untreated- or ALCK-treated GAPDH alone gave no fragment (lanes 3, 4, Figs. 3A, B). When ALCK-treated GAPDH was added to the U937 cell extract and incubated, a more intense $23-\mathrm{kDa}$ band was observed (lane 6, Figs. 3A, B). When untreated erythrocyte GAPDH was incubated with the U937 cell extract, a 23-kDa band was faintly observed (lane 5, Figs. 3A, B). It was considered that the band was derived from the damaged GAPDH contaminating in the sample. On the other hand, a rather more intense $27-\mathrm{kDa}$ band was observed in the reaction of untreated GAPDH than of ALCK-treated GAPDH with the U937 cell extract (lane 5 versus lane 6, Fig. 3B).

Sequence of N-Terminal Amino Acids of GAPDH Fragments The peptide bond digested by protease(s) in ALCK-modified GAPDH was examined. ALCK-treated erythrocyte GAPDH was incubated with the protease fractions from the U937 cell extract, and the reaction mixture was passed through a DEAE column (pH 7.4). The effluent was concentrated and separated by SDS-PAGE. When visualized by silver staining, a $17-\mathrm{kDa}$ band was also detected in addition to a $23-\mathrm{kDa}$ band (data not shown). Sequencing revealed that the N-terminal amino acid sequence of the 23-kDa fragment was GKVKVG and that of the $17-\mathrm{kDa}$ fragment was RDGRGAL. As a result of analysis using BLAST (Protein Database Search Programs), the former was identical to $1-6$ amino acids and the latter was to 196-202 amino acids deduced from human liver GAPDH cDNA (Table 1). ${ }^{17)}$

Optimal pH of Protease(s) Producing 23-kDa Fragment from GAPDH ALCK-treated erythrocyte GAPDH was incubated with gel filtration-purified fractions from the U937 extract at $37^{\circ} \mathrm{C}$ for $1 \mathrm{~h}$ in the range of $\mathrm{pH} 7.4-11$. There were apparently two effective $\mathrm{pH}$ ranges producing a $23-\mathrm{kDa}$ fragment, one was $\mathrm{pH} 7.8-8.4$ and the other was $\mathrm{pH}$ 9.0-9.8, even though the latter was found to be more effective (Fig. 4). At pHs lower than 7.0, a 23-kDa fragment was not produced (data not shown).

\section{DISCUSSIONS}

ALCK was shown to inhibit GAPDH activity in a noncompetitive manner with respect to GAP and in an uncompetitive manner with respect to $\mathrm{NAD}^{+}$. The $\mathrm{CD}$ spectrum showed a change in signal intensity in the near-UV region of

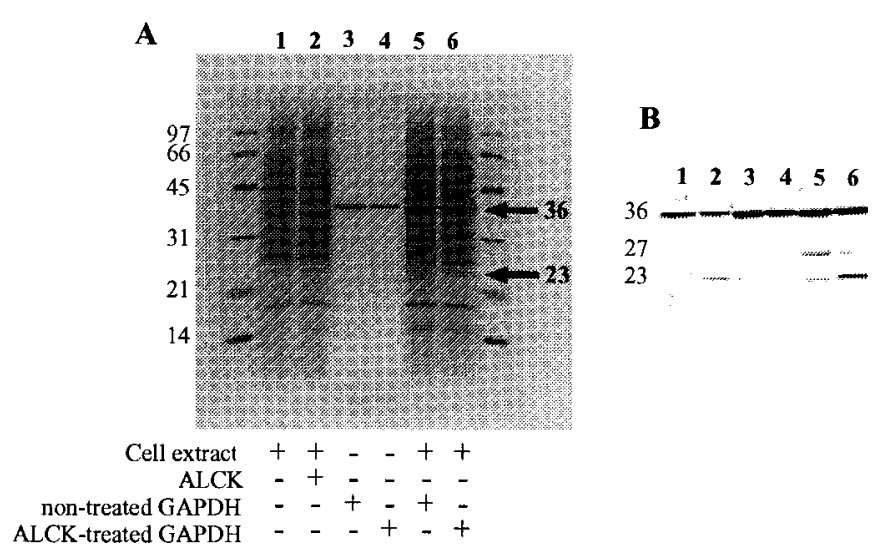

Fig. 3. Analysis of GAPDH Fragments Produced by Incubating U937 Cell Extract with ALCK or by Incubating U937 Cell Extract with ALCK-Treated GAPDH

The U937 cell extract was incubated with $1 \mathrm{mmol} / 1$ ALCK or with ALCK-treated GAPDH at $37^{\circ} \mathrm{C}$ for $1 \mathrm{~h}$. Reaction mixtures were separated by SDS-PAGE and separated products were visualized by silver staining (A) or by Western blotting (B).

Table 1. N-Terminal Amino Acid Sequence of Fragments Liberated from ALCK-Treated GAPDH

\begin{tabular}{cl}
\hline \hline Band & N-Terminal seuence \\
\hline 23-kDa fragment & GKVKVG $(1-6)$ \\
17-kDa fragment & RDGRGAL $(196-202)$ \\
\hline
\end{tabular}

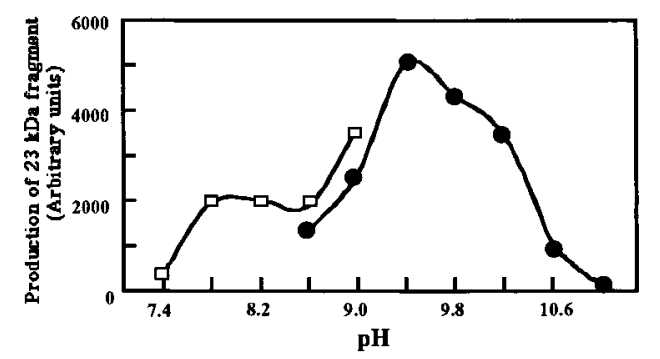

Fig. 4. Optimal $\mathrm{pH}$ of Protease(s) Producing a 23-kDa Fragment from GAPDH

ALCK-treated erythrocyte GAPDH was incubated with gel filtration-purified protease fractions from the U937 extract in the presence of $80 \mu \mathrm{mol} / 1 \mathrm{ALCK}$ in $0.02 \mathrm{~mol} / 1$ Tris- $\mathrm{HCl}$ buffer $(\square)$ or $0.02 \mathrm{~mol} / 1$ glycine- $\mathrm{NaOH}$ buffer $(-)$ at $37^{\circ} \mathrm{C}$ for $1 \mathrm{~h}$. Reaction mixtures were separated on $14 \%$ SDS-PAGE and separated products stained by Western blotting. Band intensities were analyzed using NIH image.

ALCK-treated GAPDH. The fluorescence spectrum of ALCK-treated GAPDH showed an approximately $10 \%$ increase in intensity at $330 \mathrm{~nm}$ when excited at $280 \mathrm{~nm}$. These results strongly suggest that some significant conformational changes in the vicinity of the aromatic residues in GAPDH might be induced by ALCK. It is speculated that such conformational modulation might allow protease(s) to access and digest GAPDH. Two peptide fragments, 23-kDa and 17$\mathrm{kDa}$, were found to be produced by incubating ALCK-treated GAPDH with protease(s) from the U937 extract in the experiment for Table 1. However, the 17-kDa fragment was not detected by Western blotting, because it might not be reacted with the anti-GAPDH antibody used (Fig. 3B).

The N-terminal amino acid sequences of $23-\mathrm{kDa}$ and $17-$ $\mathrm{kDa}$ fragments were GKVKVG (1-6) and RDGRGAL (196-202), respectively, suggesting that the peptide bond between $\operatorname{Trp}_{195}$ and $\operatorname{Arg}_{196}$ of ALCK-treated GAPDH was di- 


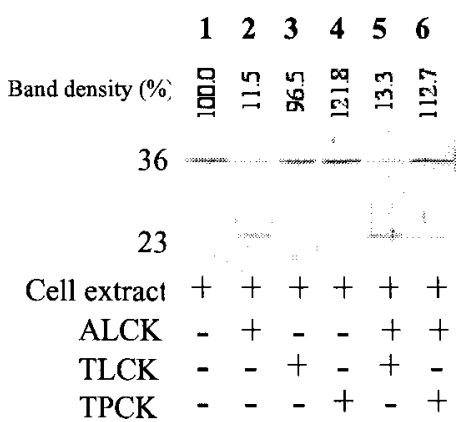

Fig. 5. Suppression by TPCK or TLCK of ALCK-Induced GAPDH Degradation in U937 Cell Extracts

U937 cell extracts were incubated with $100 \mu \mathrm{mol} / 1$ ALCK in combination with $100 \mu \mathrm{mol} / 1 \mathrm{TPCK}$ or TLCK for $3 \mathrm{~h}$ at $37^{\circ} \mathrm{C}$. Each cell extract was analyzed by Western blotting using anti-GAPDH serum. Band density values of $36-\mathrm{kDa}$ fragment were analyzed using NIH image software. These values are means for three separate experiments.

gested by protease(s). Data altogether indicate that GAPDH is modified by binding of ALCK to come a suitable substrate for some protease(s) with chymotrypsin-like activity, which digests the peptide bond at the carboxyl site of an aromatic amino acid. The amount of the $27-\mathrm{kDa}$ fragment was too small to analyze the site of digestion. However, it is suggested that the $27-\mathrm{kDa}$ fragment might be produced by some proteases other than the chymotrypsin-like protease, because it was not observed when ALCK-treated or untreated GAPDH was incubated with chymotrypsin-like protease purified from the U937 extract. GAPDH is a tetramer composed of identical subunits of 37000 molecular weight. Each subunit contains three tryptophan residues, $\operatorname{Trp}_{86}, \operatorname{Trp}_{195}$, and $\operatorname{Trp}_{312}$. The results suggest that ALCK predomominantly affects the structure around $\operatorname{Trp}_{195}$.

The degradation of ALCK-treated GAPDH in the U937 extract was partially suppressed by chymostatin, a typical inhibitor of chymotrypsin. ${ }^{2)}$ Furthermore, the degradation was inhibited by a synthetic inhibitor of chymotrypsin, TPCK (lane 6, Fig. 5), not by an inhibitor of trypsin, TLCK (lane 5, Fig. 5), which proved the similar property of the degradation enzyme to chymotrypsin. But neither chymotrypsin nor trypsin was inhibited by ALCK at the concentrations used in this experiment (data not shown). Therefore, these data exclude the direct effect of ALCK on the chmotrypsin-like protease. The protease is one of serine proteases as reported in the previous report. ${ }^{2}$ The optimal $\mathrm{pH}$ of protease was in the range of $\mathrm{pH} 9.0-9.8$. Recently, it has been demonstrated that GAPDH degradation occurs via a selective pathway of lysosomal proteolysis, ${ }^{18,19)}$ which is activated in rat liver following prolonged starvation. ${ }^{20)}$ However, the optimal $\mathrm{pH}$ for ALCK-treated GAPDH degradation in the U937 cell extract was basic; therefore, it is unlikely that lysosomal proteases with an acidic optimal $\mathrm{pH}$ are involved in the degradation of ALCK-treated GAPDH. The process of GAPDH degradation seems more complex in cells.

The unique degradation of GAPDH may be induced by some physiological factors as well as ALCK. In fact, we preliminary observed that the $23-\mathrm{kDa}$ fragment of GAPDH was increased by major product of lipid peroxide, 4-hydroxy-2nonenal. The finding prompted us to study in detail. It was possible to interpret that a minor $23-\mathrm{kDa}$ band from erythrocyte GAPDH incubated without ALCK (lane 5, Fig. 3B) was derived from a small portion of damaged GAPDH in the sample. In this study, the relationship between the degradation of GAPDH and apoptosis was not able to find out. However, it is the important point, which should be clarified in future. ALCK may be one of useful tools for elucidating its relationship.

\section{REFERENCES}

1) Yamaguchi M., Kambayashi D., Toda J., Sano T., Toyoshima S., Hojo H., Biochem. Biophys. Res. Commun., 263, 139-142 (1999).

2) Yamaguchi M., Tsuchiya Y., Chikuma T., Hojo H., Biochem. Pharmcol., 63, 1857-1862 (2002).

3) Sirover M. A., Biochim. Biophys. Acta, 1432, 159-184 (1999).

4) Glaser P. E., Gross R. W., Biochemistry, 34, 12193-12203 (1995).

5) Launay J. F., Jellali A., Vanier M. T., Biochim. Biophys. Acta, 996, 103-109 (1989).

6) Engel M., Seifert M., Theisinger B., Seyfert U., Welter C., J. Biol. Chem., 273, 20058-20065 (1998).

7) Zang W. Q., Fieno A. M., Grant R. A., Yen T. S. B., Virology, 248, 46-52 (1998).

8) Sirover M. A., J. Cell. Biochem., 66, 133-140 (1997).

9) Meyer-Siegler K., Mauro D. J., Seal G., Wurzer J., deRiel J. K., Sirover M. A., Proc. Natl. Acad. Sci., 88, 8460-8464 (1991).

10) Nakazawa M., Uehara T., Nomura Y., J. Neurochem., 68, 2493-2499 (1997).

11) Kim J. W., Kim T. E., Kim Y. K., Kim Y. W., Kim S. J., Lee J. M., Kim I. K., Namkoong S. E., Antisense Nucleic Acid Drug Dev., 9, 507513 (1999).

12) Fuertes G., Villarroya A., Knecht E., Int. J. Biochem. Cell. Biol., 35, $651-664$ (2003).

13) Wheatley D. N., Knecht E., Cervera J., Smith S., Cytobios., 74, 8196 (1993)

14) Bradford M. M., Anal. Biochem., 72, 248-254 (1976).

15) Dimmeler S., Lottspeich F., Brune B., J. Biol. Chem., 267, 1677116774 (1992).

16) Sharma K. K., Ortwerth B. J., Eur. J. Biochem., 216, 631-637 (1993).

17) Tso J. Y., Sun X.-H., Kao T., Reece K. S., Wu R., Nucleic. Acids Res., 13, 2485-2502 (1985).

18) Aniento F., Roche E., Cuervo A. M., Knecht E., J. Biol. Chem., 268 , 10463-10470 (1993)

19) Cuervo A. M., Dice J. F., Knecht E., J. Biol. Chem., 272, 5606-5615 (1997).

20) Cuervo A. M., Knecht E., Terlecky S. R., Dice J. F., Am. J. Physiol., 269, C1200-1208 (1995). 